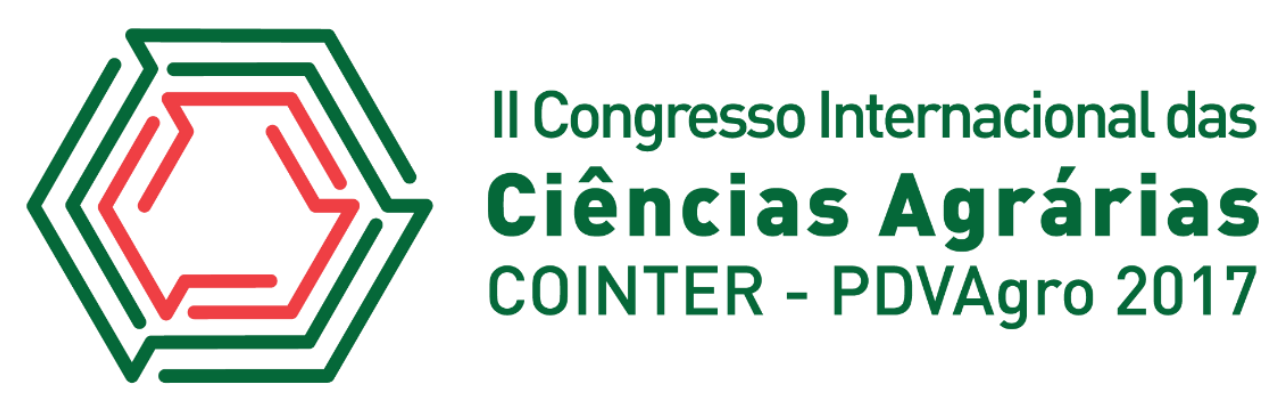

\title{
ELABORAÇÃO DE BOLO COM APROVEITAMENTO TECNOLOGICO DO BAGAÇO DA BETERRABA.
}

Apresentação: Pôster

Débora Lívia Marcolino de Souza $^{1}$ *; Carolaine Gomes dos Reis ${ }^{1}$; Rita de Cássia Cruz Gondim ${ }^{1}$; Camila Luana Pereira da Silva ${ }^{1}$; Cícera Gomes Cavalcante de Lisboa ${ }^{2}$

\section{Introdução}

A beterraba é uma planta herbácea pertencente à família Amaranthaceae existem várias espécies dentre elas a sacarina e açucareira é uma hortaliça tuberosa de coloração avermelhada, bastante nutritiva por apresentar em sua composição vitaminas, minerais, carboidratos, ácidos como fólico que desenvolve papel importante para formação do feto durante a gestação essa hortaliça é originária da Europa e da África (FEDERAL et al., 2016).

Bolo são produtos da confeitaria os quais são obtidos através da cocção adequada de massa preparada com farinhas, amidos, féculas e outras substâncias alimentícias, sendo doces ou salgados, recheados ou não (Resolução - CNNPA nº 12, de 1978).

Assim o presente estudo teve por objetivo elaborar bolo da fibra da beterraba analisando sensorialmente a sua aceitação frente a um produto obtido por "resíduo" alimentar.

\section{Fundamentação Teórica}

A beterraba (Beta vulgaris) é uma hortaliça que possui atributos de alimento funcional, pois ela possui substâncias bioativas (licopeno) e pigmentos (carotenoides e flavonoides), tem características antioxidantes que protegem contra doenças cardíacas, problemas vasculares, cerebrais e também fortalece o sistema imunológico (RIBEIRO et al ,2014).

\footnotetext{
${ }^{1}$ Graduanda do Curso de Tecnologia em Alimentos - IF Sertão-PE/Salgueiro *deboralvida@gmail.com

2 Docentes doutora do Curso Superior Tecnologia em Alimentos - IF Sertão-PE/Salgueiro liviacali@hotmail.com
} 
Bolo é um produto assado, preparado a base de farinhas ou amidos, açúcar, fermento, podendo conter leite, ovos, manteiga, gordura e outros ingredientes que caracterizam o produto (Resolução - CNNPA no 12, de 1978).

Os resíduos gerados pela agroindústria, como o bagaço, semente de frutas, estão sendo utilizado como técnicas para minimizar os impactos ambientais gerados pelas mesmas, como alternativas para o uso destes resíduos, estudos estão sendo realizado para gerar novos produtos alimentícios, os quais tem o potencial de substituir parcial ou total a farinha de trigo na preparação de bolos, biscoitos, pães e entre outros produtos, com maior valor agregado, para o consumo humano (SILVA, 2017).

A análise sensorial é realizada para averiguar através de respostas prestadas pelos julgadores às várias sensações que se originam ao provar o produto estas sensações indicam o quanto os julgadores apreciaram ou não as amostras neste julgamento, os indivíduos, por meio dos próprios órgãos sensórios utilizando os sentidos da visão, olfato, audição, tato e paladar assinalam suas percepções na fixa de análise (IAL, 2008).

\section{Metodologia}

O processamento do bolo foi realizado no Laboratório de vegetais, no IF Sertão PE, campus Salgueiro. Para a elaboração do bolo de beterraba foram adquiridos os ingredientes no comércio local. Para a extração do bagaço foi utilizado liquidificador onde foi adicionada a beterraba com 50 $\mathrm{ml}$ de suco de limão e água, logo em seguida foi coado e reservado o bagaço. Os ingredientes utilizados foram: farinha de trigo (duas xícaras) para mesma quantidade do bagaço da beterraba (2:2) ou 50\%, uma xícara de óleo, duas xícaras de açúcar, três ovos inteiros (clara e gema) e uma colher de sopa de fermento.

Primeiramente, em um liquidificador foi adicionado o bagaço (fibra) da beterraba, a qual já estava reservada, juntamente com o óleo e os ovos, a mistura foi liquidificada e reservada. Em uma tigela foi misturada as matérias-primas secas: farinha de trigo, fermento e açúcar, e em seguida adicionada a mistura do liquidificador, sendo realizada a homogeneização de todos os ingredientes. A forma foi untada com margarina e polvilhada com açúcar. O forneamento do bolo foi feito em fogão industrial pré-aquecido por 40 minutos. Para o recheio foi preparado um mouse de cenoura que consiste nos seguintes ingredientes: uma lata de leite condensado e suco concentrado de duas cenouras grandes, seguindo de homogeneização e refrigeração. Foi realizada uma divisão no meio do bolo para colocar o recheio (mouse), o qual ainda foi utilizado o bagaço da cenoura para 
polvilhar. Para a cobertura foi utilizado bagaço da beterraba misturado com creme de leite, conforme figura 1.

Figura 1: Bolo do bagaço da beterraba coberto com recheio de beterraba. Fonte: Própria.

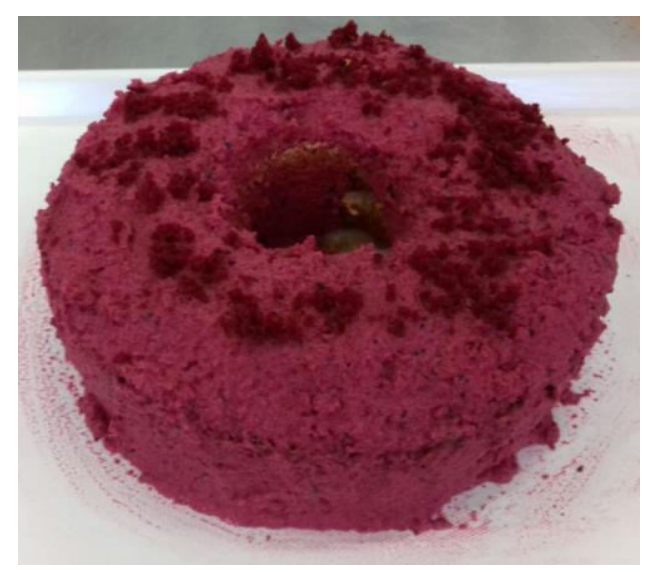

A análise sensorial foi realizada na referida instituição de ensino, por 50 julgadores não treinados, avaliando a amostra em uma escola hedônica estruturada de nove pontos variando de 1 (desgostei extremamente) a 9 (gostei extremamente). As amostras foram codificadas com três números aleatórios. Os parâmetros julgados foram: cor, sabor, textura, aroma e aceitação global. A amostra foi avaliada ainda quanto a intenção de compra em uma escala de 5 pontos, variando de 1 (certamente não compraria) a 5 (certamente compraria). Os julgadores eram compostos por $58 \%$ do sexo feminino e $42 \%$ do sexo masculino, na faixa etária de 14 a 38 anos de idade. Os dados foram tabulados no programa Microsoft Excel 2013, através de porcentagem.

\section{Resultados e Discussões}

Os resultados para o teste de aceitação do bolo, os quais foram obtidos através de porcentagem, podem ser observados na tabela 1, onde os resultados encontram-se divididos por escores.

Tabela 1: Resultado obtido em porcentagem do teste de aceitação do bolo elaborado com o bagaço da beterraba. Fonte:

Própria.

\begin{tabular}{|c|c|c|c|c|c|c|}
\hline \multirow{2}{*}{ Escores } & \multirow{2}{*}{ Classificação da escala } & \multicolumn{5}{|c|}{$(\%)$} \\
\cline { 3 - 7 } & & Cor & Sabor & Textura & Aroma & Aceitação Global \\
\hline 1. & Desgostei extremamente & 0 & 0 & 0 & 0 & 4 \\
\hline
\end{tabular}




\begin{tabular}{|c|c|c|c|c|c|c|}
\hline 2. & Desgostei muito & 0 & 0 & 0 & 0 & 0 \\
\hline 3. & Desgostei moderadamente & 2 & 2 & 2 & 4 & 0 \\
\hline 4. & Desgostei ligeiramente & 0 & 6 & 0 & 2 & 0 \\
\hline 5. & Indiferente & 12 & 4 & 8 & 0 & 4 \\
\hline 6. & Gosta ligeiramente & 10 & 10 & 4 & 6 & 8 \\
\hline 7. & Gosta moderadamente & 24 & 12 & 18 & 28 & $\mathbf{3 8}$ \\
\hline 8. & Gosta muito & $\mathbf{3 6}$ & $\mathbf{3 8}$ & $\mathbf{3 8}$ & $\mathbf{3 0}$ & 28 \\
\hline 9. & Gosta extremamente & 16 & 28 & 30 & $\mathbf{3 0}$ & \\
\hline
\end{tabular}

Verifica-se na tabela 1 que o bolo foi bem aceito, obtendo percentual de escore 8 "Gosta muito" para os parâmetros de cor, sabor, textura e aceitação global. Para o quesito aroma as notas variavam nos escores 8 a 9 (Gosta extremamente).

Os resultados encontrados foram superiores aos obtidos por OZORES et al. (2015) os quais elaboraram bolos enriquecidos com farinha de maracujá com percentuais de 5-10 e 15\% da farinha do maracujá, obtendo valores melhores para os bolos de 5 e $10 \%$, os quais não diferiram entre si ao nível de 5\% de probabilidade, a preparação com $20 \%$ obteve menor aceitação devido ao sabor residual do maracujá. Observa-se que o produto (bolo) do presente trabalho, na proporção de 2:2 ou $50 \%$ do bagaço da beterraba, obteve melhores pontuações por não apresentar sabor residual forte, possuir cor chamativa (sem necessidade de corante para a cobertura), aroma bem característico tornando o bolo bem saboroso e atrativo.

No trabalho de CARVALHO; BASSO (2016) em estudos sobre o aproveitamento integral dos alimentos em escola pública, elaboraram bolo da casca da banana e pizza de legumes, os quais obtiveram resultados um pouco inferiores ao trabalho em questão, em média as notas atribuídas para o bolo e a pizza variaram entre gostei moderadamente - gostei muito, quando comprado ao bolo de beterraba este apresentou melhor nota com classificação gostei muito, ambos os trabalhos tem grande potencial no aproveitamento destes alimentos.

O bolo do bagaço da beterraba apresentou boa aceitação pelos julgadores, no quesito intenção de compra ficando em média no escore 5 "certamente compraria” como mostra a figura 2. 
Figura 2: Resultado do teste de intenção de compra de bolo elaborado com bagaço da beterraba. Fonte: Própria.

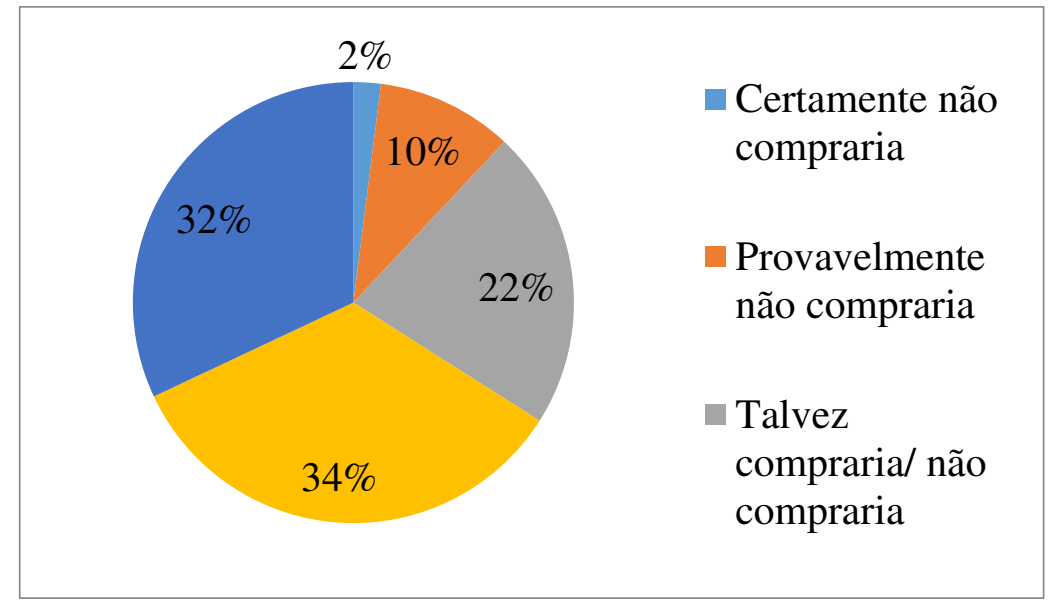

MAURÍCIO et al. (2012) em seu estudo sobre bolo de cenoura com e sem glúten: desenvolvimento da formulação e aceitação do produto, obtiveram maior aceitação do que o trabalho em questão, pra o bolo BGOM- bolo com glúten e óleo de milho o qual a formulação se aproximou mais do trabalho em questão. Este maior percentual de aceitação de $45 \%$ pode estar atrelado a utilização do óleo de milho que proporcionou melhores características sensoriais.

\section{Conclusões}

Conclui-se que o bolo elaborado com adição de resíduos é um potencial alternativa na elaboração desses produtos, com percentual de 32\% de aceitação, sendo viável o aproveitamento desses resíduos pelas indústrias que geram constituindo um desenvolvimento sustentável.

\section{Referências}

CARVALHO, C.C.; BASSO, C. APROVEITAMENTO INTEGRAL DOS ALIMENTOS EM ESCOLA PÚBLICA NO MUNICÍPIO DE SANTA MARIA - RS. Disciplinarum Scientia. Série: Ciências da Saúde, Santa Maria, v. 17, n. 1, p. 63-72, 2016.

FEDERAL, U. et al. DETERMINAÇÃO DA COMPOSIÇÃO CENTESIMAL A PARTIR DE DOIS MÉTODOS DE SECAGEM PARA A PRODUÇÃO DA FARINHA DE BETERRABA (BETA VULGARIS, L. - FAMÍlIA AMARANTHACEAE). Visão Acadêmica, v. 17, p. 22-35, 2016.

Instituto Adolfo Lutz. Métodos físico-químicos para análise de alimentos. Análise Sensorial. IV Ed. São Paulo, 2008.

MAURÍCIO, A.P.; BUCARLES, P.B; BOLINI, H.M.A.; SOUSA, V.M.C de. Bolo de cenoura com e sem glúten: desenvolvimento da formulação e aceitação do produto. Revista Agro@mbiente Online, v. 6, n. 3, p. 250-257, setembro-dezembro, 2012. 
OZORES, B.; STORCK, C. R.; FOGAÇA, A. de O. ACEITABILIDADE E CARACTERÍSTICAS TECNOLÓGICAS DE BOLO ENRIQUECIDO COM FARINHA DE MARACUJÁ. Disciplinarum Scientia. Série: Ciências da Saúde, Santa Maria, v. 16, n. 1, p. 61-69, 2015.

RIBEIRO, J.S.; MACAGNAN, C.C ; PINHEIRO, L.N.; FREITAS, M.S.; DRUZIAN, S.P.; TERRA, L. DESENVOLVIMENTO DE UM ALIMENTO FUNCIONAL A PARTIR DA DESIDRATAÇÃO OSMÓTICA E SECAGEM EM ESTUFA DA BETERRABA. In: X Congresso Brasileiro de Engenharia Química Iniciação Científica. v. 1, n. 1, p. 8-11, 2014.

SILVA, D. A. UTILIZAÇÃO DA FARINHA DE RESÍDUOS DE ACEROLA E UMBU CAJÁ NA PRODUÇÃO DE BOLO TIPO CUPCAKE. SÃO CRISTÓVÃO/SE, 2017. 107 p. Tese (Desenvolvimento e Meio Ambiente). Universidade Federal de Sergipe, UFS, 2017. 